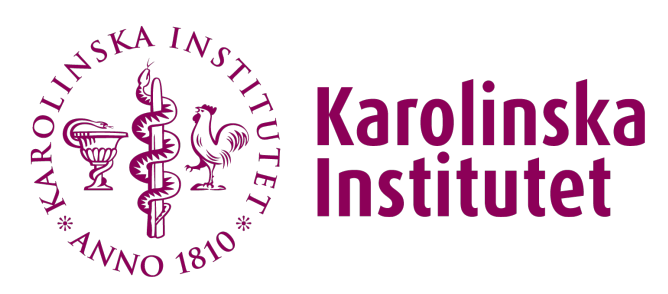

Karolinska Institutet

http://openarchive.ki.se

This is a Peer Reviewed Published version of the following article, accepted for publication in Twin Research and Human Genetics.

\title{
Exposure to air pollution from traffic and neurodevelopmental disorders in \\ Swedish twins
}

Gong, Tong; Almqvist, Catarina; Bölte, Sven; Lichtenstein, Paul; Anckarsäter, Henrik; Lind, Tomas; Lundholm, Cecilia; Pershagen, Göran

Twin Res Hum Genet. 2014 Dec;17(6):553-62.

http://doi.org/10.1017/thg.2014.58

http://hdl.handle.net/10616/45603

If not otherwise stated by the Publisher's Terms and conditions, the manuscript is deposited under the terms of the Creative Commons Attribution-NonCommercial-NoDerivatives License (http://creativecommons.org/licenses/by-nc-nd/4.0/), which permits non-commercial re-use, distribution, and reproduction in any medium, provided the original work is properly cited, and is not altered, transformed, or built upon in any way. 


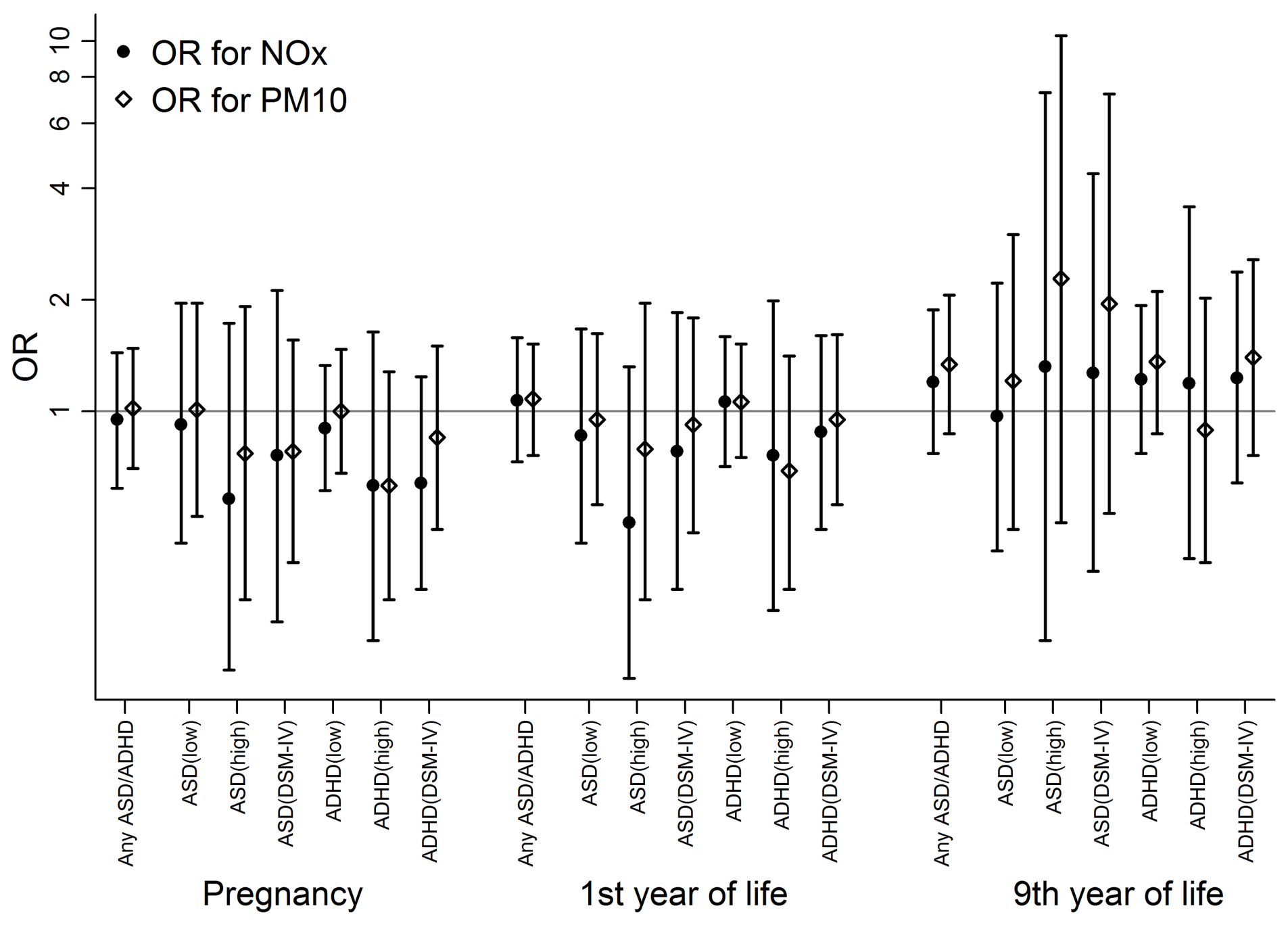

